\title{
ANALYTICAL JURISPRUDENCE IN MID- TWENTIETH CENTURY: A REPLY TO PROFESSOR BODENHEIMER
}

\author{
H. L. A. Hart $\dagger$
}

Professor Bodenheimer has subjected my inaugural lecture "Definition and Theory in Jurisprudence" to a criticism ${ }^{1}$ which is short but long enough I hope, to have stirred me from dogmatic slumbers: these, it is well to remember, may overcome one who believes he is saying something new, just as much as those who are consciously and conscientiously treading well-worn paths. In any case my exposition of my own views must have been very inept (or perhaps just ill-adapted for export to the United States) to have left as intelligent a critic as Professor Bodenheimer with the impression which he has that I really am a kind of academic saboteur who, under the guise of stressing the importance of newer methods in analytical inquiries, is really attempting to demonstrate the futility of analytical jurisprudence. Professor Bodenheimer's picture of my activities is novel and entertaining, though scarcely flattering; but I must hasten to assure him and my readers that the sober truth is very different. I do indeed consider analytical jurisprudence, if pursued with the appropriate methods, to be an important subject capable of making an important contribution to at least one aim which I think I must have in common with Professor Bodenheimer: namely, the increase of our understanding of the character of law as a means of social control.

I hope to make this article something more than a mere reply to the specific points which Professor Bodenheimer has raised, and to show the reader in general terms why $I$ think analytical inquiries are worth pursuing and how recent developments in philosophy have provided it with a means of getting off to a fruitful new start. So in what follows I shall try to state how analytical jurisprudence properly pursued can advance our understanding of the law and what I conceive its function in a legal education to be.

In part because of the importance of these two main issues and also because $I$ wish to avoid boring the reader by a detailed discussion

$\dagger$ Professor of Jurisprudence, Oxford University, Member of the English bar.

1. Bodenheimer, Modern Analytical Jurisprudence and the Limits of Its Usefulness, 104 U. PA. L. REv. 1080 (1956). 
of those points where Professor Bodenheimer has innocently misquoted, misstated or misunderstood what I have said or what I meant, I shall relegate these points to a footnote. ${ }^{2}$ I must, however, draw attention here to the fact that most of Professor Bodenheimer's misquotations or misunderstandings of what I said seem to spring from a single pervasive error of considerable importance; it is indeed one which has been recognized by contemporary philosophers as a source of confusion in many different fields. It is this: Professor Bodenheimer either cannot distinguish or thinks it of no importance to distinguish between, on the one hand, law and legal concepts and, on the other, theories of or about law, and defuitions of legal concepts. So he makes me look sillier than I hope I am, by treating the observations which $I$ in fact make about legal theories and about the character of definitions of legal concepts as if these observations had been made about laze and legal concepts themselves. Thus, to take one example, he quotes me as saying of legal concepts such as that of a corporate body that they "tend to have their heads in the clouds" whereas I had in fact said that theories concerning the nature of corporate entities "seem

2. Professor Bodenheimer's version of what I wrote in Hart, Definition and Theory in Jurisprudence, 70 L.Q. REV. 37 (1954) and the original are as follows:

Bodenheimer

(a) "He [Hart] cannot see any justification for the rise of whole schools of jurisprudence combating each other for no better purpose than to answer a few 'imnocent' questions which, in his opinion, can be handled easily by a developed legal system without assuming this incubus of theory." "

Bodenheimer, supra note 1 , at 1080 .

(b) "The difficulty with legal definitions, according to his [Hart's] diagnosis, lies in the fact that they do not have the straightforward connection with counterparts in the world of reality which most non-legal, ordinary words have. The factual relations and events which these terms describe, he points out, are never the exact equivalent of the legal words ...."

Id. at 1081 . (c) "[M] etaphorically expressed, legal concepts tend to have their head in the clouds.

Ibid.

(Emphasis added.) (a) "[S]omething is wrong with the approach to definition; can we really not elucidate the meaning of zords which every developed legal system handles smoothly and alike without assuming this incubus of theory."

Hart, supra at 39.

(b) "[E]fforts to define words like "corporation,' 'right' or 'duty' reveal that these do not have the straightforward connection with counterparts in the world fact which most ordinary words have .... [T] The expressions we terder in our definition - are never precisely the equivalent of these legal words ...."

$I \dot{d}$. at 38.

(c) "Though these theories spring from the effort to define notions actually involved in the practice of a legal system they rarely throw light on the precise work they do there. They seem to the lawyer to stand apart with their head at least in the clouds; and hence it is that very often the use of such terms in a legal system is neutral between competing theories. For that use "can be reconciled with, any theory, but is authority for none." "

Id. at 40 . 
to the lawyer to stand apart with their heads at least in the clouds" precisely because the actual use in a legal system of such legal concepts "can be reconciled with any theory but is authority for none."

Nothing less than this confusion between theories of law on the one hand and law on the other, and between definitions or analyses of legal concepts on the one hand and these concepts themselves, could have led Professor Bodenheimer to say that I do not advocate "going outside the boundaries of pure legal reasoning" 3 and to ascribe to me the quite fantastic view that "law is a self-contained science which does not need the assistance of other social disciplines for its proper functioning." 4 I had indeed already said in "Definition and Theory in Jurisprudence" 5 that we had learnt to our profit from the theories of the American Realists how small a part deduction from predetermined premises plays in the judicial process, though I had protested that this valuable lesson was blurred if it was presented as a matter of definition of law or right. Perhaps I need hardly insist that even in England, even in Oxford, we have come around to the view that law "for its proper functioning"-which I suppose means if the decisions rendered by courts are to be satisfactory and intelligent-needs recourse to other disciplines than law. ${ }^{6}$ But since Professor Bodenheimer has misunderstood me, let me here assert emphatically that I certainly do hold this view: yet I combine it with the view that the time the student can afford to spend on jurisprudence is likely to be better spent on the close and careful analysis of fundamental legal notions and those lying on the boundary of a legal system than in assimilating what he can of other social disciplines. Of course this latter view of mine may be wrong; but there is nothing inconsistent in holding both these views. Professor Bodenheimer is surely guilty of very poor reasoning if he deduces that I hold the long outmoded "conceptualist" or "mechanical" view concerning "law and its proper functioning" which he ascribes to me from the fact that I think the analysis of legal concepts very important and a much more important educative tool than sociological jurisprudence.

However, Professor Bodenheimer's mistake on this point brings to light something of quite general importance. He has indeed some excuse (though no justification) for identifying analytical jurisprudence with the absurd view that law in its proper functioning needs

3. Bodenheimer, supra note 1 , at 1080 .

4. Ibid. (Emphasis added.)

5. "So too the American Realist theories have much to tell us of value about the judicial process and how small a part deduction from predetermined premises may play in it. . ." Hart, supra note 2 , at 40 .

6. See p. 964 infra. 
no recourse to other disciplines and that "correct" legal decisions can be simply deduced by strictly logical means from purely legal premises; for this is in fact a misunderstanding of analytical jurisprudence which has long been common on the continent of Europe. It rests on the assumption that analytical jurisprudence could only have any place if judicial decisions were strictly deduced from purely legal premises and if all that courts needed, having found the facts, was the capacity for formal logical reasoning from predetermined premises. Proceeding from this mistaken assumption, it is then argued that anyone who thinks analytical jurisprudence important must take this illusory view of the judicial process. Yet in fact neither the classical analysts like Austin nor contemporary analysts have ever held this absurd view of the functioning of law. Austin, who may rank as the principal proponent of the view that an autonomous subject of analytical jurisprudence - to be distinguished from sociological and other types of inquiries concerning law-was worth pursuing, himself clearly recognized that judges made law though they often pretended to find it, and he was prepared to say that they made law sometimes very much better than the official legislator did. ${ }^{8} \mathrm{He}$ therefore was quite alive to one fact which makes it absurd to suppose that the courts operate with formal logical reasoning alone. Secondly, he was also alive to another fact which makes this "mechanical" view of the judicial powers false: samely that legal concepts are both vague and (what is different) ambiguous. Nevertheless Austin thought it of the greatest importance, if we are to understand law, that we pursue the close analysis of the words such as "obligation," "duty" or "right," even though we have to allow for a multiplicity of meanings and for cases where the concepts are vague so that we could not have, as he says in a striking phrase, more than "fallible tests" of whether a given fact-situation was covered by it or not. ${ }^{9}$ Perhaps it is hardly necessary to remind the reader that modern analysts like Hohfeld have also stressed the ambiguities of concepts such as that of a right.

In fact it is plain that one of the results of analytical jurisprudence itself has been and is increasingly the demonstration of the "open

7. See, e.g., Friedmann, Legal Theory 209 (1947): "Analytical jurisprudence seeks to achieve certainty by relying on an allegedly complete logical system."

8. See Austin, The, Province of Jurisprudence, Determined 191 (Library of Ideas ed. 1954).

9. "The positive mark of sovereignty and independent political society is therefore a fallible test. ... The ... notion of an independent political society, is therefore vague and uncertain. ... [ [ $\mathrm{L}]$ aw strictly so called is not free from like difficulties. What can be more indefinite, for instance, than the expressions, reasonable time, reasonable notice, reasonable diligence? Than the line of demarcation which distinguishes libel and fair criticism; than that which constitutes a violation of copyright; than that degree of mental aberration which constitutes idiocy or lunacy?" Id. at 204-05, 207. 
texture" or vagueness of the periphery of the concepts used in the daily life of the law and the many ways in which rules of law involving such concepts fail to determine uniquely decisions in particular cases. Shortly put, this means that it is confusion and indeed false to assert the identity of analytical jurisprudence with "conceptualism" or "mechanical" jurisprudence or (to use Professor Bodenheimer's words) with the view that "law is a self-contained science which does not need assistance of other social disciplines for its proper functioning." 10

II

In 1952 when, after some nine years of legal practice and seven years teaching of philosophy, I became Professor of Jurisprudence at Oxford, I formed the view that analytical inquiries into the nature of law and legal concepts had come to a premature standstill. This was in part due to the perfectly legitimate and beneficial diversion of juristic attention to the many problems presented by the fact that legal rules are vague at their periphery, and so, often fail to determine uniquely a court's decision. Emphasis on this phenomenon had led some jurists (the "rule-sceptics") to doubt in more or less exaggerated terms the very possibility of describing a legal system even partly in terms of rules; others had been stimulated to make perhaps more fruitful inquiries as to the criteria which courts should use if reasonable decisions were to be given in various situations when they were faced with what in a sense are "gaps" in the legal system. Others still had seen that the rational treatment of problems of the penumbra involves consideration of the purposes "behind" the law and had invoked the traditional terminology of Natural Law-sometimes also with some of its traditional confusions-to express their views.

For these and other reasons attention had been diverted from those aspects of law not troubled by the special problems of vagueness or uncertainty and as a result, with the exception of the work of Hohfeld and Kelsen, very little of value had been added in the twentieth century to what Bentham and Austin had done in analytical jurisprudence. Yet it seemed to me patent that questions remained concerning those parts of law which are relatively stable and certain and which constitute the conceptual framework characteristic of legal thought: these questions either had remained unanswered or had been given only very confused answers.

Even those writers who, like Hohfeld and Kelsen, had made advances on their predecessors in these matters seemed to me not suffi-

10. Bodenheimer, supra note 1 , at 1080 . 
ciently to have realized the special characteristics of concepts involved in the use of rules, nor to have seen the multiplicity and variety of different phenomena embraced under the exceedingly general terms "law," "norm" or "rule." Hence many important aspects of the subject had been quite neglected; these remained to be revealed by a more patient examination of legal concepts and legal language with new tools and with a new sensitivity to logical and linguistic distinctions. Among these neglected problems was the identification of more of the many different uses made in a legal system of legal rules which are reflected in legal language: jurists seemed often to have ignored the fact that rules are not only susceptible of being obeyed or disobeyed but of radically different operations. For example, when rights are claimed, a rule is invoked; when a legal power is exercised a rule is acted on; when a particular case is found to fall within the scope of a general rule, a rule is applied. These and many other different relationships to rules need elucidation ${ }^{11}$ if we are not disastrously to oversimplify our accounts of what rules are and of what law is, or to jump to hasty conclusions about the precise character of its connexion with other means of social control such as "morals"-itself an umbrella term sheltering many different objects requiring analysis.

Of course the later analysts like Kelsen had seen that the tools used by Austin and Bentham were too crude to do justice to the phenomenon of law. Austin's insistence that "the key to the sciences of jurisprudence and morals" ${ }^{12}$ was the notion of a command (defined as the expression of a desire when the party to whom it is directed is liable to an evil from the other in the event of disobedience) had proved to be very misleading. Even a statute, which among the types of legal rules bears the most similarity to what Austin defined as a command,

11. These things must be considered if we are to free the concept of a rule from confusion with the concepts of a command or a habit which has been too common in juristic theory. Much of the extravagance obscuring the valuable insights of many "Realist" writers was due to their initial failure to raise such preliminary analytical questions as: What is it (what is meant by) "to act on a rule," "to apply a rule," "to accept a rule or regard it as binding"? How do these things differ from (and resemble) behaving with predictable regularity or acting habitually? At least some "rule-scepticism" was due to the rule-sceptic insisting that no judicial behaviour could count as the acceptance of rules because the alleged rules were subject to exceptions, or only conditionally applicable to specific cases or were used by the judge not to reach his decision but as a justification for a decision reached intuitively. Yet a scrutiny of what is ordinarily meant by the expression "He observed the rule" (e.g., requiring him to stop at a red traffic-signal) would show that none of these facts exploited by the rulesceptics are inconsistent with it.

Dissatisfaction with the inadequacies of "positivist" definition of law in terms of command and habits or predictable regularities among other things has lead some to seek something better in the remarkably unclear terminology of natural law. Yet some at least of the "positivist" errors could be corrected just by taking seriously the analysis of the notion of a rule.

12. Austin, op. cit. supra note 8 , at 13. 
differs from it in ways which must be understood and precisely stated if the nature of law is not to be misrepresented. Kelsen of course made points of this character when he insisted, first, that a statute may come into being even though those who enact it have not the "desire" required in the Austinian conception of a command and, second, that no commands (in the Austinian sense) would constitute a statute except where there was in existence some rule giving authority to those who enacted the statute to make laws by enactment. ${ }^{13}$

Yet these insights of Kelsen (and other insights of Hohfeld) were marred by the failure to resist the temptation to oversimplify the heterogeneous and complex phenomena of law and to reduce the varieties of legal rules to some simple form. This oversimplifying "reductionist" drive, so often found to be a snare in many other branches of philosophy, is evident, for example, in Kelsen's insistence that really the "genuine norms" are those rules ("primary norms") which direct officials of the system to apply sanctions under certain conditions, and that the essence of a legal system is best revealed if we restate all legal rules in the form of conditional directions to officials to apply sanctions. ${ }^{14}$ The importance of preserving the distinctions marked by normal terminology and resisting the reduction of the variety of different types of legal rules to a single type in this or any other manner had never been clearly or convincingly stated; and yet the logical and other motives inspiring this and other forms of oversimplification or reduction needed to be exposed before it could be said that we had really understood even those parts of a legal system which are relatively fixed and stable and so were able to distinguish law satisfactorily from other forms of social control and see its relations to them. ${ }^{15}$

Apart from these major problems, many questions also seem to me to have remained either unasked or wrongly answered; among

13. Kifsen, Gengral Theory of Law and State 30-31, 33-34, 143-44 (1946).

14. Id. at 61 : "Law is the primary norm, which stipulates the sanction. . ."

15. Kelsen's reduction of laws of all sorts (including constitutional law) to parts of "sanction-stipulating norms" (i.e., to the conditions of conditional directions to officials to apply sanction) tells the prospective litigant or criminal all he may want to know about law. Yet like Holmes' "bad-man" theory it dogmatically suppresses (as if obviously of inferior importance) other vital aspects of law for which the ordinary formulation of legal rules allows a place. Some legal rules (e.g., against homicide) require people to act or abstain from acting in certain ways whether they wish to or not; others (e.g., laws specifying what must be done to make a valid will) provide legal facilities for giving effect to indivduals' wishes. The former type requires abedience; disobedience is an offence normally punishable; the latter types are to be complied with and non-compliance leads to nullity. A theory which obliterates the distinction between these two types presenting rules of the second type as mere conditions for the applications of sanctions (e.g., against a defaulting executor) surely obscures two radically different uses of law and gives a distorted account of law as a social phenomenon. For the way in which different formulation of legal rules are often correlated with different social situations, see DAUBE, FORMS OF ROMAN LEGISLATION (1956). 
them was the question as to what was meant by the "existence" of a legal rule or indeed a legal system and how the existence of, say, a particular statute within a legal system differed from the existence of a rule of social practice such as the rule that we stand up when "The Star-Spangled Banner" is played. Or, in what way does a fundamental rule of constitutional law specifying the competence of a legislature exist? Until these complex ambiguities in the very notion of the existence of laws or rules had been cleared up, no progress, I thought, could be made with understanding what lies at the root of a legal system; and one could not say how far Austin's characterization of it as a habit of obedience or Kelsen's as a postulate or hypothesis whose "validity" was assumed was correct or fallacious. Until we understood those things, certainly it seemed to me we lacked understanding of what law is and of the type of social structure to which we refer in asserting that a legal system exists among a population.

However, as a general preliminary to dealing with those outstanding problems of analysis, it seemed to me vital first to remove one age-old source of trouble in analytical jurisprudence, which had led many theorists down profitless paths. Very often progress in a science is held up not because wrong answers have been given but because the wrong sort of question has been asked; and this, I think, had for long been the case with analytical inquiries into the nature of legal concepts. Those inquiries had taken the form of requests for definition issuing in the standard type question "What is X?," e.g., "What is duty?," "What is a right?," "What is a corporate body?," "What is possession?" "What is a rule?" The "What is $X$ ?" form of question takes a single word and asks what it means (or worse, "stands for") and this had led to confusion because it insidiously suggests the type of answer to be given must be answered in the specification of some thing or quality with which the word is supposed to be directly aligned. With many concepts such a definition is innocuous. It might well be said that the word "chair" is directly aligned with and so "means" or "stands for" a certain type of thing, in that case an article of furniture. Similarly the word "red" may be said to be directly aligned with a certain discernible type of color. But legal concepts are different: their relation to fact is more complex and indirect and much in need of clarification, and if they are submitted to the usual mode of definition, distortion or mystery results. The unsatisfactory use in definitions of a right, a duty or a corporate entity of the terms "fictions," "collections" or "predictions" had in part at least been due to this cramping framework imposed upon the inquiry into the character of these concepts by a method of definition which makes a frontal attack 
on single words, although of course, as I had already said in my inaugural lecture, other motives have contributed to these theories. Accordingly, I have advocated in my lecture the application in the analysis of fundamental legal concepts of a different technique. This is in fact a very old technique advocated, as I said there, by Bentham, though the fundamental insight could be found in many philosophers such as Frege. ${ }^{16}$ The technique I suggested was to forego the useless project of asking what the words taken alone stood for or meant and substitute for this a characterization of the function that such words performed when used in the operation of a legal system. This could be found at any rate in part by taking the characteristic sentences in which such words appear in a legal system, e.g., in the case of the expression "a right," such a characteristic sentence as " $X$ has a right to be paid $Y$ dollars." Then the elucidation of the concept was to be sought by investigating what were the standard conditions in which such a statement was true and in what sort of contexts and for what purpose such statements were characteristically made. This would get away from the cramping suggestion that the meaning of a legal word is to be found in some fact-situation with which it is correlated in some way as simple and straightforward as the way in which the word "chair" is correlated with a fact-situation and substitute for this an inquiry into the job done by such a word when the word was used in a legal system to do its standard task.

The advantage to be gained by abandoning ${ }^{17}$ the attempt to define single words in favor of the elucidation of the use of words in

16. See The Foundations of Arithmetic $\$ 62$ (Austin transl. 1953): "How then are numbers to be given to us if we cannot have any ideas or intuitions of them? Since it is only in the context of a proposition that words have any meaning our problem becomes this: To define the sense of a proposition in which a number word appears.

17. Professor Bodenheimer objects to this method of elucidating legal concepts that it is merely to substitute a long explanation for the concise definition of single words found in dictionaries, or "to describe legal terms in three or four sentences rather than in one brief phase." Bodenheimer, supra note 1, at 1081. But the two types of definitions do not differ merely in length but in their objectives. Generally a dictionary definition is designed to teach the conventional use of expressions to those ignorant of the meaning of particular words and does so by giving as synonyms words which it is assumed the reader knows. $C f$. the definition of a right cited from the Restatement of Property by Professor Bodenheimer as "a legally enforceable claim of one person against another, that the other shall do a given act or not to do a given act." Ibid.

But analytical inquiries are not answered by this form of definition since the proferred synonyms (in this case "claim") present the same features as called for the original inquiry. This is so because the form of perplexity about legal concepts which lead to, e.g., realist definitions of a right as prediction of what officials will do or to the complaints (voiced, e.g., by the Scandinavian jurists) that it is impossible to identify the facts corresponding to a right does not originate in ignorance of the conventional use of words in an incomplete understanding of special or anomalous features of this use. So a form of definition (explanatory definition) is needed which will show how words like that of a "right" derive their meaning from the way in which they function in connection with legal rules, for this is what makes them different from ordinary words and hence perplexing. 
characteristic legal contexts may be exemplified in the light this throws on a particular legal phenomenon which has also important analogues outside the law. In any legal system it is the case that rules provide legal powers of different kinds which may be exercised by words spoken or written in given certain circumstances; when used by persons duly qualified in appropriate circumstances, words have certain legal effects. Examples of this are the words of grant (in England known as "operative" words) in a deed or assignment or a lease, the words used at the crucial point of making a bequest in a will (e.g., "I hereby bequeath") and the language of enactment used by legislators ("It is hereby enacted"). This use of language (and accordingly the type of concept involved) differs strikingly from what may well be considered the more familiar use of language to "describe" or state facts;" here by contrast words are used in the sense to do something, namely, actually to change the legal position by creating obligations, conferring or transferring rights, and bringing about legal changes in various complex ways. Outside the law, analogous uses of language, which none of the conventional categories employed for the classification of language (e.g., "descriptive," "emotive," "imperative") reveal, can be found in the christening ceremony ("I hereby give this child the name $X$ "), in the words used in an apology ("I hereby apologize") and of course most prominently in the words used in the making of a promise. To elucidate this use of language is not merely to point out a fact about words, though of course it is in part that; it is also to characterize a type of activity which is very central to the life of the law. This forces upon our attention how superficial that view of legal rules is which conceives of law as much traditional theory has conceived of it, as consisting of rules which are simply obeyed or 'applied, or used as the bases of prediction. What we have in the operative use of words is something different and revealing about the form of life represented by the use of law as a means of social life.

The elucidation of the operative use of language typical of the law would, I think, be important for its own sake; it has, however, been a phenomenon which has occasioned very great difficulties to jurists of many different sorts in the analysis of legal phenomena. The whole attempt on the part of jurists to convey precisely what a legal transaction or juristic act (act in the law, Rechtsgeschäft) is, has been confused just for the lack of a sufficiently sharp tool by which to detect this special use of language. Hagerström, whose work translated recently into English ${ }^{18}$ has attracted some considerable attention in this

18. Hagerstrom, Inguiries Into the Nature of Law and Morals (Broad transl. 1953). 
country, concentrated his energies on the elucidation of this phenomenon, but with only partial success. He saw with great clarity that words in the law are often used in ways different from those of normal descriptive speech or writing so that the words of an offer are misdescribed as a statement of intention; yet his positive account is surely absurd. He held ${ }^{19}$ that no explanation could be given of the capacity recognized in a legal system to create obligations, to transfer rights or otherwise to change legal situations by the use of language-except that this must rest on the superstitious belief, on the part of those who participate in such operations, in the magical power of words to transform a supra-sensible world of rights and duties, which is taken to exist over and above the ordinary world of fact.

Such a conclusion really abandons the task of elucidating something essential in legal thinking and indeed in life according to law. Hagerström indeed found the phenomenon, which he characterized as the "magical use of words," widespread in Roman law and devoted his work to an examination of it in that system, where the suggestion of the survival of a "magical" "ceremonial" use of words might have a certain plausibility. But he appears not to have noticed that just as much, and therefore just as little, ground for the characterization of a legal use of language as magical is to be found in the modern conveyance, the modern statute and the modern will. To understand this aspect of the law we need to ask under under what standard conditions, and for what purpose, is a sentence of the form " $X$ hereby conveys unto $Y$ " correctly and effectively used. Given a sufficient awareness of the radically different types of functions for which language is used, and a determination not to oversimplify or "reduce" to some favored model, whether "descriptive," "emotive" or "imperative," a satisfactory elucidation can be given.

\section{III}

I shall now try to anticipate some objections ${ }^{20}$ which may be stirring in an intelligent reader's mind if he has gotten thus far. He may reasonably ask a number of questions.

19. Id. at xvii (editor's preface) and 229-328.

20. These objections include Professor Bodenheimer's criticisms except those already answered. He makes four principle charges:

(1) That the method of elucidation $I$ propose merely substitutes long explanations for short dictionary-type definitions;

(2) That all legal concepts have a vague penumbra where courts must have recourse to social factors; an elucidation of concepts which is unaccompanied by a thorough consideration of these social factors is no substantial improvement;

(3) That legal terms are used in manifold and inconsistent ways and the types of definition I propose would be too brief to depict of all these;

(4) That the methods I propose involve exposition of large parts of positive law and so analytical jurisprudence will be almost fused with positive law and unnecessary as a separate discipline. 


\section{a) Why do we need analysis? How can analysis help?}

Surely a critic might say that once we have put aside those parts of a legal system which, because of the vagueness of legal rules, present us with penumbral problems, for the solution of which we must have recourse to other disciplines, we are left merely with the elements which have fixed and stable meaning. These may be learned (perhaps best in the introductory parts of legal textbooks dealing with different branches of the law) and once learned they present no difficulty; both for the student and the practical lawyer their use proceeds smoothly and raises no questions. I think this attitude is at the root of Professor Bodenheimer's objections when, after insisting that all legal concepts have a penumbra of vagueness, he proceeds to say:

"[An] explanation of concepts, unaccompanied by a thorough consideration of the social factors which may justify an expansion, contraction or re-formation of the concept, cannot be regarded as a great step forward. . . ." 21

This objection neglects two things. First, vagueness is not the only feature of legal concepts which renders them puzzling; their departure from normal or more familiar uses of language in various ways may require attention quite apart from any fringe of vagueness by which they may also be characterized. Secondly, there is the much more important fact that it is characteristic not only of the use of legal concepts, but also of many concepts in other disciplines and in ordinary life, that we may have adequate mastery of them for the purpose of their day-to-day use; and yet they may still require elucidation; for we are puzzled when we try to understand our own conceptual apparatus. We may know how to use these concepts, but we cannot say how or describe how we do this in ways which are intelligible to others and indeed to ourselves. We know, and yet do not fully understand, even quite familiar features of legal thinking-much in the way perhaps that a man may know his way about a familiar town by rote without being able to draw a map of it or explain to others how he finds his way about the town. This surely is the predicament which makes the philosophical elucidation of concepts necessary and philosophy has always found its chief stimulus in this predicament. The crudest and simplest example of the predicament is that of a man who says that he can recognize an elephant when he sees one but he could not define it if asked; the most complex example perhaps of the same predicament is the capacity to use mathematical notions in various

21. Bodenheimer, supra note 1 , at 1083. 
complex ways which may co-exist with great fundamental unclarity as to many features of mathematical concepts and their relations to other types of concepts. This, of course, the philosophy of mathematics has done something to resolve. Perhaps the best and most succinct expression of this need for elucidation of a concept whose use in daily life presents no difficulty is St. Augustine's answer to the question: "What is time"? ${ }^{22}$

"What then is time? If no one asks me, I know; if I wish to explain it to one that asketh, I know not; yet I say boldly, that I know, that if nothing passed away, time past were not; and if nothing were coming, a time to come were not; and if nothing were, time present were not."

In the law, similarly, we need clarification of fundamental notions or concepts which we can master adequately for the purposes of ordinary use in addition to the definitions offered in a textbook dealing with a substantive branch of the law. These, generally speaking, cannot constitute an adequate substitute for a separate though connected discipline of analytical jurisprudence; the textbook by its form of definition is concerned to teach the use of certain concepts to students who have no acquaintance with that use. By contrast, a philosophical definition or explanatory elucidation is designed not to teach the use to those who are ignorant of it, but to explain features which are still puzzling to those who have mastered this use.

If again I may use a very simple example to bring home my point, consider how little success has attended even the explanations of a notion very fundamental in law, that of an obligation. Austin defined this as the "chance or likelihood" that one who had been commanded to do or to abstain from doing something would suffer some evil in the event of disobedience. ${ }^{23}$ Of course this definition is linked to the Austinian definition of law in terms of a command, and is unsatisfactory on this score alone. Yet I know of no satisfactory re-definition of this notion in terms more consistent with later insights that the notion of a rule or "norm" is more suited to the analysis of law than the notion of a command.

Austin's analysis is essentially in terms of prediction: the chance or likelihood of suffering a sanction. This really was not queried by jurists of the "realist" school, who of course make great use of the notion of prediction and, no doubt because of their inherent "rulescepticism," scarcely attended to the distinctive features of a rule (in

22. Confessions of St. Augustine 11.14.7.

23. AustTn, op. cit. sispra note 8, at 14-18. 
contrast with a habit or prediction) in providing an analysis of legal phenomena. Yet if we turn back to Austin, not with the question "What is an obligation?," but with the question "Under what standard conditions is a statement of the form ' $X$ recognizes an obligation' true?," it is possible not only to see Austin's mistakes but to distinguish distinct social situations which are confused by any such analysis as his. His definition of obligation in terms of the chances of suffering a feared evil or sanction is at the best a poor analysis of the notion of being obliged to do something, and very misleading as an analysis of having an obligation. A woman threatened by a gunman is correctly said to have been obliged to hand over her purse if she acts through fear of the gunman's threats, but it would be absurd to say on these facts that she had an obligation to hand over her purse to him. Different logical consequences attach to saying respectively "She had an obligation to do it" and "She was obliged to do it," and the concept of an obligation can be elucidated by making these explicit. It would, for example, be contradictory to say, "She was obliged to hand over her purse but did not do so"; but it is not at all contradictory to say, "She had an obligation to hand over the purse but did not do so." Similarly, it would be a contradiction to say, "She was obliged to give back the purse but feared no unpleasant consequences of failing or refusing to do so; but it is not contradictory to say, "She was under an obligation to hand over the purse but feared no unpleasant consequences of failing or refusing to do so."

These differences trace the outline of two distinct though related concepts, and so of two distinct types of social situations. The crucial difference is this: to say of someone that he had an obligation to do an action is neither to assess the chance of his being made to suffer in the event of his not doing it nor to make a psychological statement about him, e.g., that he did it from fear of unpleasant consequences. It is, on the contrary, to indicate his position in relation to a rule requiring those in situations such as this to act in a specified way. Rules (of this sort) exist when a given social group treats certain types of action (either directly specified or indirectly specified as those designated by a legislative authority) as standards of behavior. This in its turn means (i) that deviation from certain types of action (unlike deviations from mere habits) are generally criticized as lapses and are accepted as rendering legitimate the use of various types of serious pressure, coercion or punishment ("sanctions") against those who deviate, (ii) that reference to the general acceptance of the standard are accepted as reasons for or justification for demands for compliance even though in any particular case there may be no "chance" of the sanction for non- 
compliance being exacted and no fear of it. Hence, "He was obliged to" and "He had an obligation to" may diverge in a particular case where there is nothing to fear from non-compliance. It is of course true that in a normal legal system, where sanctions are normally exacted and likely, such cases of divergence will be exceptional, but the distinction remains and is important for the understanding of the notion of an obligation and of one important type of rule.

\section{b) Is analytical jurisprudence concerned merely with words?}

Perhaps it be evident from what I have already written that my answer to this question is "No." Rather, we have in the new analytical weapons, and in the new awareness which recent philosophy has brought of the radically different types of function which language performs, a vehicle for better understanding the world in which and about which we use language of various sorts. The question "Is analysis concerned with words or with things?" incorporates a most misleading dichotomy. Perhaps its misleading character comes out in the following analogy. Suppose a man to be occupied in focusing through a telescope on a battleship lying in the harbor some distance away. A friend comes up to him and says, "Are you concerned with the image in your glass or with the ship?" Plainly (if well advised) the other would answer "Both. I am endeavoring to align the image in the glass with the battleship in order to see it better." It seems to me that similarly in pursuing analytical inquiries we seek to sharpen our awareness of what we talk about when we use our language. There is no clarification of concepts which can fail to increase our understanding of the world to which we apply them. The successful analysis or definition of complex or perplexing terms or forms of expression have certainly some of the essential elements of the discovery of fact, for in elucidating any concept we inevitably draw attention to differences and similarities between the type of phenomenon to which we apply the concept and other phenomena. In so doing we gain a wider and a more detailed conspectus of both words and of things we are in effect making for ourselves a map of a wider area than that we are used to considering apart from such analytical inquiries. I would say that the example used in the preceding section serves at once to discriminate the concept of "being obliged to" and "having an obligation" to do something and, on the other hand, to demarcate radically different social situations or social behavior which need to be distinguished with precision if we are to understand the conceptual framework of the law in which the concept of obligation plays a prominent part. 
c) If words are vague or ambiguous, has not analytical jurisprudence an impossible task to perform?

Again it seems to me that this is a suggestio falsi. The contention is that since most legal expressions have a certain hard core of meaning and then a penumbra of vagueness, or since many notions like that of a right are ambiguous, it follows that to start on the analysis of this aspect of these concepts is to attempt a Sisyphean task involving the recording of myriads of divergent usages of forms. Surely this is enormously to exaggerate the degree of irrational chaos which permeates our thought and language in the law. Undoubtedly the situation referred to by the critic here has to be clearly confronted, but with this recognition must go also what is surely a fact, that the divergencies at the penumbra of legal concepts and the ambiguities are not without rhyme or reason of a certain sort and that a rationale may be found (no doubt by hard work) behind many apparently discrepant uses of the same term.

Two analytical principles must be called in to deal with this phenomenon. The first is that in the analysis of concepts we need first to establish what may be called the paradigm or standard case of the use of an expression. Surely, to take a humble example, no one would say that it is hopeless to embark upon the analysis or definition of the expression "a vehicle" because we may well be uncertain both in legal and other contexts whether to include in this term skates, toy motor cars, sledges, as well as the standard cases of a motor car or a horse and cart. The position usually is that we can distinguish for any concept a standard case and then the phenomenon of vagueness shows itself in the fact that there are strains in our thought, and so in our language, inclining us to assimilate to the standard case those cases which have only some of these features-there is also a counter strain inclining us to withdraw the concept in the absence of certain of these features. The analytical task here, having established the features which constitute the paradigm case, is to examine the various motives that may incline us one way or the other in dealing with the borderline case.

The second principle is one more germane when the question of ambiguity (not vagueness) is in issue. Sometimes the surface variety of applications of a given term show that we need to make a distinction between defining a general term and giving criteria for its application in different ranges of cases. This is evidently so, to take a non-legal example, with concepts such as "winning a game." The definition of this term might be given in such words as "obtaining more points 
which count in a competitive game." But of course what constitutes points (the criteria as distinct from the definition of winning) will vary for different games; hence we need to distinguish the multiplicity of different criteria for winning various games from any uniform definition that might be given of the notion of winning. This obviously has applications to the notion of a legal system. We might be able to provide a definition of "legal system" in uniform terms, while also recognizing that the criteria for the application of what constituted a valid law could vary from system to system. Traditional theories of jurisprudence have suffered from failure to recognize this possibility of dealing with what may on the face of it look like ambiguity, but is in fact a structural complexity of certain concepts which need in their analyses just this distinction between definitions and criteria. The analysis of the concept of justice may similarly be aided by a distinction between (1) the definition of its meaning in terms perhaps of a stable principle of securing that proper claims to equal or unequal treatment are recognized and (2) shifting criteria used in determining what claims are proper.

Thirdly, we must, especially with regard to law, be always on the lookout for the possibility that the principle or rationale which accounts for a seeming variety of different phenomena being given the same term may take different forms. Aristotle himself was well aware of the absurdity of the prejudice which makes many thinkers insist that whenever we use the same term of different instances this must be because the instances have certain "common qualities" : he distinguished many other varieties of principles leading to the application of the same terms to different things. He also saw that many important expressions were such that the instances to which they were applied were linked not by the possession of common qualities but by varying relationships to a central notion or, in other cases, by analogy. ${ }^{24}$ To fail to realize the complexities of structure in our concepts, which have led to this linguistic situation, is to be gravely hampered in dealing with moral and legal notions where these features are present in full force. Just as when we speak, first, of a man being "healthy"; second, of a complexion being "healthy"; third, of exercise being "healthy," we do not mean that each of the subjects to which the expression "healthy" is applied have common characteristics-rather, we mean that the healthiness of a complexion and the heathiness of exercise have a certain causal or other relationship to the concept of a healthy person. So in considering the "spread" of many legal no-

24. Cf. Aristorle, Nichomachean Ethics 1.6, where the applications of the term "good" to different things is explained in these ways. 
tions we should be alive to just this mode of explication. Professor Bodenheimer has mentioned the bewildering ambiguity of the concept of a right as defeating any project of analytical jurisprudence which it would be sense to attempt; ${ }^{25}$ but, as I pointed out in a footnote in my inaugural lecture, ${ }^{26}$ at least the four cardinal distinctions drawn by Hohfeld (which are in effect merely four different uses of the expression "a right" common in our legal language) can be elucidated by exhibiting how all of them center around a focal point, namely the notion of an individual's choice. Certain uses of the expression "a right" indicate that the law is concerned to give effect in certain circumstances to an individual's choice, whereas others merely signify that in certain respects that choice is unimpeded. ${ }^{27}$

Lastly, it may well be the fact that we find in the usage of legal expressions wide divergences either in the mouths of different speakers or separating the usages of different jurisdictions. Professor Bodenheimer has drawn attention to some of these divergences; but it seems to me that here, when presented with such divergences, our attitude should be not "This is chaos; this is the limit of analysis and its utility; nothing more is to be said." On the contrary, more often it will be the case that we are faced with divergent usage because the whole conceptual background with which the divergent speaker or writer approaches the subject makes him, as it were, see the classification of phenomena differently from the way the standard user sees it. We have, therefore, in analytical jurisprudence, at this point an important and exciting task to bring out the motives for divergence from a standard and with it the whole difference in the structure of thought that leads to divergent classification.

25. Bodenheimer, supra note 1 , at 1082-83.

26. Hart, supra note 2, at 49 n.15.

27. Professor Bodenheimer cites as an example of the manifold and often inconsistent uses of the expression "a right" the cases of (1) a right to kill in self-defense; (2) a right to inherit property and others. He says that these fall outside Hohfeld's scheme which he finds similar to my "formula." Bodenheimer, supra note 1 , at 1082 \& n.14. It is clear that Hohfeld's distinction of four different senses of the general term "a right" for which he proposed new names ("claim," "privilege," "power" and "immunity") is not exhaustive but marks off only four principle cases. Nevertheless (1) a right to kill in self defense is surely an example of that sense of a right which he termed "privilege" since it is the absence of a duty (not to kill). Certainly (2) a right to inherit property cannot be simply identified with any of Hohfeld's four senses of right but it is surely a perfectly comprehensible extension of that sense of right (Hohfeld's "claim") which denotes an enforceable claim; for to say that a person has a right to inherit is to say that under the law as it is he may acquire in certain events an enforceable clain to a dead person's property. Hohfeld's scheme is imperfect in other ways but Professor Bodenheimer's objection that the law uses Hohfeld's terms "privilege" and "liability" in ways different from Hohfeld is quite irrelevant. Hohfeld never claimed that these terms were generally used in law with the meaning he assigned to them: he merely adopted them to distinguish the four different senses of a "right" which had been confused for lack of distinctive names. 
As an Oxford colleague of mine has said, finding a divergent usage even on the lips of a really loose speaker would not be a reason for abandoning the analysis of concepts any more than a scientist's discovery of an electron rotating in the reverse direction from the normal should lead him to conclude that he had better abandon physics. ${ }^{28}$ It would be just dogmatic to take the view a priori that no explanation of the abnormal phenomenon could be found or was worth a search.

\section{d) How is analytical jurisprudence related to the ordinary study of the separate branches of the law?}

Professor Bodenheimer objects that if, as I have urged, legal terms can only be satisfactorily elucidated by studying examples of their actual use in a legal system, then "analytical jurisprudence becomes fused-or almost fused-with positive law." ${ }^{20}$ He concludes that if this is so, there is no need for analytical jurisprudence since the definition of legal concepts (or their "hard core," which is alone definable) can be adequately done by the special disciplines themselves.

This is a mistake, due mainly to neglect of the distinction already stressed between definitions teaching the use of legal expressions to a student ignorant of them and elucidation of the perplexities concerning the use of expressions which remain when that use is known. These rernain because the use of those expressions differ from that of ordinary non-problematical expressions in many subtle ways. The student, e.g., of the law of property, and the student of jurisprudence both need explanation of, say, words of grant (operative words), but they need them for different reasons and the explanation must therefore take different form. What is puzzling about the concept of an obligation, a right, a corporate person or a juristic act, involving the use of operative words, at the level of jurisprudential inquiries, need not be, and usually is not, adverted to in the teaching of the particular branches of the law. A student can be taught at least at a fairly advanced level how to use correctly the expressions "a right," "an obligation," "a conveyance" without considering the correctness of juristic analyses of these in terms (respectively) of prediction of what courts will do or chances of incurring a sanction, or declarations of intention. Yet such jurisprudential theses have been put forward in the effort to explain the function and so the meaning of these expressions; and explanation

10 (1956-1957). A Plea for Excuses, in Procendings of the Aristotelian Societx

29. Bodenheimer, supra note 1 , at 1085. 
is needed because their use is obscurely felt to be anomalous compared with familiar fact-stating or descriptive language.

Hence what jurisprudence should provide is a clearer conspectus or map of those features of legal concepts which differentiate them from ordinary, relatively well understood types of concepts, and exhibits clearly their distinctive mode of functioning. For this purpose examples of their use in the law must be taken but it will be quite unnecessary to examine all the detail which the student of the substantive law will require to know. Thus, to bring home the special operative use of words in the law, it will be enough to take a few examples of this very general feature and usually it will be quite superfluous to study what differentiates particular sub-species (leases, wills, enactments). So too, in order to elucidate the concept of an obligation, it will not be necessary to investigate the differences between contractual obligations and those of torts; still less the difference in specific torts. On the other hand it will often be necessary to stress features taken for granted or ignored as obvious in the teaching of the particular branch of the law and to show how these are involved in the structure of the problenratic concept. The result of such analytical inquiries-unlike the teaching of the substantive branches of the law-is to increase the understanding of legal concepts, not only by exhibiting their place in legal thinking but also by displaying clearly the precise way in which they differ from the simpler or more familiar concepts of ordinary "descriptive" or fact-stating discourse.

\section{IV}

Lastly, as to the pedagogics of the subject: I have expressed, ${ }^{30}$ and I shall briefly explain the view that the limited time which the student can spend on jurisprudence is better devoted to analytical inquiries than to sociological jurisprudence.

(a) I do not by any means consider that the student's analytical inquiries should be confined to exclusively legal concepts. In the article from which Professor Bodenheimer quotes my views on this matter, I said that the great value of jurisprudence lay in the opportunities it presented to teach men at a formative period of their mental life "to continue to think clearly and precisely even when, as in the case with the fundamental notions involved in the structure of a legal system or lying on its boundaries, the subjects themselves may be vague." 31 By

30. Hart, Philosophy of Law and Jurisprudence in Britain (1945-1952), 2 AM. J. Comp. L. 355 (1953).

31. Id. at 363. (Emphasis added.) I later used the expression quoted by Professor Bodenheimer which omits the words emphasized above. Id. at 364 . This may have mislead him. 
this perhaps obscure phrase I meant to convey that, as well as strictly or exclusively legal concepts, the student's analytical inquiries should certainly cover concepts such as those of Justice, Natural Law, Punishment and Responsibility, which are closely interrelated with law and have traditionally been included in the study of jurisprudence. My own practice is certainly to require students to examine in some detail the classical theorists on these topics, e.g., Aristotle's discussion of Justice in Book V of the Nichomachean Ethics, and to compare this with an analysis of the use we make in ordinary life of the expressions "just," "fair" as distinct from other elements in the vocabulary of morals. Here too philosophy has opened up some new approaches. It now seems profitable to ask under what types of conditions do we use the "just/unjust" dichotomy (as distinct from "good/bad") rather than to ask baldly "What is justice?" It is worth remembering the possibility already mentioned of splitting the analysis between a definition of justice in terms of a stable principle of securing recognition of proper claims to equal or unequal treatment and varying criteria for determining when such claims are proper. So too in considering such different cases as those where we say of (i) a law, (ii) the application or administration of the law, (iii) compensation, that these respectively were just or unjust, it is well to be alive to the possibility that what unifies these three cases may be a different relationship to a central principle.

The detailed analysis of those major concepts of morality with which law is most closely interrelated seems to me more valuable both as a form of mental training and as means of providing the student with a wider perspective in which to view the law than training in the actual evaluation and criticism of this or that legal institution in the light of different sociological or psychological theories or conceptions of social purpose. To say this is not to deny the value of these alternative approaches and of course I agree that there can and should be no absolute severance of analytical inquiries from consideration of bodies of empirical knowledge relevant to the criticism of social or legal institutions. It would, for example, be absurd to attempt to analyze the concept of punishment or responsibility or to determine the meaning and relevance of the notions of retribution, deterrence or reform without considering certain general theories of human nature and investigating the claim that psychological discoveries have made the continued use of these concepts irrational, or shown the need for modification, if they are not to defeat the social purpose they are believed to serve.

(b) I have no doubt that a student who in the formative years of his intellectual life acquires skill in the close analysis of concepts, even 
if this is pursued to somewhat "academic" extremes, acquires a technique which is readily transferable to other fields. It has been my own observation confirmed by many lawyers and pupils that such a skill is of the utmost value in increasing the student's capacity to deal with the concrete branches of the law; yet it is not something which can be conveyed, at least not so well conveyed by simply concentrating on those branches. The level of abstraction required in the wider analytical inquiries of the sort that I have mentioned and the complexity of concepts at this level make, I think, of their analysis a unique educational instrument.

(c) Finally, it is, I hope, clear from all that I have said that I do not regard analytical jurisprudence as exclusive of other forms of jurisprudence. There is room, of course, for other approaches, although I have my own reasons for preferring the analytical as an educational tool. On the other hand, I think that no candid student of sociology could deny that, valuable as the insights have been which it has provided, the average book written in the sociological vein, whether on legal topics or otherwise, is full of unanalyzed concepts and ambiguities of just that sort which a training in analysis might enable a student to confront successfully. Both psychology and sociology are relatively young sciences with an unstable framework of concepts and a correspondingly uncertain and fluctuating terminology. If they are to be used to illuminate us as to the nature of law, these sciences must be handled with care and with a sensitivity to the types of ambiguity and vagueness, and also other linguistic anomalies, which the student will best learn to appreciate in handling the leading concepts of the law in an analytical spirit. I hope it will not be found offensive if $I$ take as an illustration of this point, one of those questions which Professor Bodenheimer mentions as an example of the "many rewarding tasks other than formal analysis that jurisprudence is called upon to perform for the benefit of the law." $\mathbf{3 2}$

These "rewarding tasks" include "the difficult question, highlighted by the opposing views of Austin and Ehrlich, as to whether government or society is the true author of the law. . . ." 33 Surely this question cannot be attacked without hopeless confusion until we have settled what, in a context such as this, could be meant by the expression "the true author of the law." Does this mean: (a) the chief or more important causal influence in determining what laws are made and/or enforced? If so, what is meant by saying that one influence is more important than another? Or does "true author of the

32. Bodenheimer, suprat note 1 , at 1085.

33. Id. at 1086. (Emphasis added.) 
law" mean (b) a person having a superior moral claim to determine what shall be law? Or, (c) a legislative operation regarded by the courts of the legal system as the criterion of what rules are to be applied as law in the courts? All these are questions of analysis and I hope (and believe) that a training in analytical jurisprudence would secure that the student would see that no progress could be made with Professor Bodenheimer's "highly difficult" question without first answering these analytical preliminaries as to their very meaning. Is it not at least possible that when the meaning or meanings of "true author of the law" has been investigated and settled, the question itself need not detain us long? 